\title{
Opiniáo PÚblica e TECNOLOGIA: OS IMPACTOS do Big DATA NOS ESTUdos DE OPINIÂO PÚBLICA SOB O OLHAR DO PRAGMATISMO
}

\author{
Vinícius Romanini ${ }^{1}$ \\ Pedro Caldas ${ }^{2}$
}

\begin{abstract}
Resumo: Neste artigo, investiga-se como o estudo da opinião pública é influenciado pelas pesquisas de opinião pública, na medida em que estas funcionam como meios para inquirição da realidade. Com o crescente movimento de datificação do mundo, transformaçóes científicas e tecnológicas emergem e impactam o campo de estudos da opiniáo pública. Têm-se hoje, de um lado, as pesquisas de opinião tradicionais e, do outro lado, as pesquisas possibilitadas pelo advento do Big Data. Para além de um apanhado de protocolos metodológicos, cada um dos modelos abarca em si um significado de "opiniáo pública", remontando ao velho embate epistemológico entre teoria e metodologia presente nesse campo de estudo. Descrevem-se as principais diferenças entre esses dois modelos, para, em seguida, sob o olhar do pragmatismo de Peirce enquanto teoria de significaçáo, analisar a transiçáo pela qual se está passando, nos dias de hoje.
\end{abstract}

Palavras-chave: Pesquisa de opinião pública. Big Data. Significado. Pragmatismo.

\section{INTRODUÇÃ́O}

O objeto deste trabalho está circunscrito à problemática das pesquisas de opiniấo pública, no atual estágio da chamada "era do Big Data", em que o modelo de pesquisa de opiniáo pública tradicional é confrontado com as

\footnotetext{
${ }^{1}$ Professor na Universidade de São Paulo (USP), São Paulo, SP - Brasil. (DD https://orcid.org/00000001-6558-0550. E-mail: vinicius.romanini@usp.br.

${ }^{2}$ Mestre pela Escola de Comunicaçóes e Artes da Universidade de São Paulo (USP), São Paulo, SP Brasil. (D) https://orcid.org/0000-0002-9170-573X. E-mail: pedrocaldas@usp.br.
}

https://doi.org/10.1590/0101-3173.2021.v44n4.30.p375

\section{(i)}


metodologias emergentes de análise de dados coletados em mídias sociais. Há, atualmente, a convivência de dois principais modelos para a produçáo de pesquisas de opinião pública em larga escala, cada qual estruturado a partir de princípios epistemológicos distintos - e, até certo ponto, contrastantes: um modelo tradicional, baseado em amostras colhidas por meio de surveys; e um novo modelo de pesquisa, possibilitado pelas técnicas de coleta de dados dos usuários de mídias sociais on-line na Internet, tais como Facebook e Twitter. $\mathrm{Na}$ era do Big Data, bancos de dados e suas lógicas de processamento passam a ser a sintaxe básica da informação e da comunicação social, a ponto de se constituírem como um novo gênero cultural e de embasarem uma nova ideologia, chamada de dataísmo (VAN DIJCK, 2017, p. 41).

Em meio a tantas diferenças percebidas entre o modelo de pesquisa de opinião pública tradicional e o novo modelo, uma delas será privilegiada por nós, ao longo deste artigo. Trata-se de uma distinção no significado do conceito de opiniấo pública, ou seja, uma distinçáo no que se entende por opiniâo pública, segundo cada modelo. Como veremos, cada um dos modelos possui uma base epistemológica que determina não apenas as metodologias aplicadas, mas o próprio entendimento do objeto "opiniāo pública" que se procura estudar e que guia a produção das pesquisas. A escolha do nosso referencial teórico (o pragmatismo) - que servirá também como ferramenta para nossa análise - se deu justamente em vista disso.

Não existe uma definição convencionalizada para o termo "opinião pública”. Um empecilho recorrente na sua definição é a possibilidade multidisciplinar de abordagens entre as áreas e subáreas do conhecimento que estudam o objeto "opinião pública”. Dentre elas, poderíamos citar, ao menos, a filosofia, a história, a sociologia, a ciência política, a psicologia social, a comunicação social, a estatística etc., cada uma das quais se utilizando das suas lentes epistemológicas, teorias, hipóteses e metodologias próprias. A modernidade trouxe consigo diversos pensadores, os quais se debruçaram sobre o estudo da filosofia política e abordaram o estudo das opinióes e crenças da sociedade, enquanto temas de alta relevância. Alguns exemplos importantes são Maquiavel, Hobbes, Locke, Montaigne e Rousseau, sendo esse último o precursor do uso de "opinião pública" como conceito filosófico e político.

Algo comum visto entre essas abordagens modernas é o caráter teórico e complexo atribuído ao estudo e à tentativa de explicação do funcionamento da opiniáo pública. Isso mudou com a invenção das pesquisas de opinião pública e com o estabelecimento de um olhar estritamente empírico e quantificador 
do objeto em questão. O termo "opinião pública” passou a significar - ou ser entendido como - a agregação ou a soma de opiniōes individuais e, sob os olhares do senso comum, a "opinião pública" torna-se sinônimo dos resultados das próprias pesquisas realizadas para estudá-la (GOIDEL, 2011, p. 11). Essa interpretação foi muito criticada, durante o século passado, acusada de simplificar a opiniáo pública, por meio de uma perspectiva quantitativa rasa. Com a chegada e a consolidação da Internet, do Big Data e, em especial, com a ascensão das mídias sociais ao posto de esfera pública digital, renova-se o debate sobre a opiniáo pública enquanto objeto teórico que nasce das relaçóes sociais complexas e conversacionais. Ao mesmo tempo, também é reacendida a discussão sobre o que é a opinião pública.

Com o desenvolvimento deste trabalho, buscamos responder à seguinte questão: pensando a partir do pragmatismo de Peirce (enquanto uma teoria de significação), qual a diferença entre esses dois modelos de pesquisa de opinião pública, na medida em que eles funcionam como meios de inquirição da realidade? Para responder a essa pergunta, estabelecemos por objetivo apresentar as principais diferenças entre cada modelo, as quais, note-se, não são excludentes, mas complementares. Faremos isso, descrevendo o contexto em que surgem, o objetivo esperado com o emprego de um modelo ou outro, os principais protocolos metodológicos utilizados e, finalmente, o que se entende por opinião pública, em cada caso. Em seguida, abordaremos essas diferenças, a partir dos princípios do pragmatismo de Peirce, o qual terá sido discutido na primeira parte do trabalho.

\section{O pragmatismo de Peirce}

O pragmatismo é uma doutrina que foi ampla e profundamente estudada no decorrer do século XX, e muito disso se deve a Peirce e seus escritos, publicados ainda no século XIX. As produçóes intelectuais que compuseram as discussóes sobre o pragmatismo, na virada entre esses dois séculos, influenciaram de tal modo as filosofias seguintes que seria impossível a nós, no espaço que nos cabe, abordar tudo de maneira proveitosa.

Ao pensarmos o pragmatismo como uma teoria única, mas com múltiplos exponentes - a qual abarca inúmeros filósofos e pesquisadores -, deveríamos poder encontrar um ponto em comum que garantisse tal unidade e os colocasse todos sobre uma mesma base. Essa unidade, como o próprio nome pode nos sugerir, reside no fato de o pragmatismo carregar consigo uma 
íntima relação com a noção de prática, conectada à teoria, e de pensamento, associada à ação (DE WAAL, 2007, p. 18). De Waal nos explica, no entanto, que existem, para além da unidade trazida por essas noçôes, duas possíveis compreensóes para o que seria de fato o pragmatismo, entre os próprios teóricos dessa corrente. Uma primeira compreensão se refere ao pragmatismo enquanto método para determinação do significado de palavras e conceitos, ou seja, um critério de significação. Ela está presente no texto de Peirce, intitulado Como tornar nossas ideias claras, publicado no ano de 1878, na primeira versão da máxima pragmática - que veremos em breve.

Uma segunda compreensão do pragmatismo faz com que alguns o considerem uma teoria sobre a verdade. Apesar dos adeptos dessa interpretação serem diversos, Peirce discordava dela:

Peirce sustentava que são duas questóes completamente diferentes e que o pragmatismo, tal como expresso em seu princípio, é estritamente um critério de significaçáo. Aquilo a que frequentemente se refere como a teoria pragmatista da verdade resulta, então, da aplicação do critério pragmático de significação ao conceito de verdade. Para Peirce, "verdade", assim como "dureza", "identidade", "simultaneidade" etc., é somente um daqueles conceitos dos quais se deve ter uma concepção pragmatista. O que se chama de teoria pragmatista da verdade é, assim, um desenvolvimento do desejo de limpar o discurso filosófico. Por conseguinte, a teoria pragmatista da verdade é uma consequência do pragmatismo e, certamente, uma consequência importante, mas não uma característica definidora dele. (DE WAAL, 2007, p. 23).

Podemos notar que ambas as compreensôes possuem raízes nas teorias de Peirce, mas só uma delas é, efetivamente, como Peirce a elaborara, sendo a outra, segundo o próprio autor, uma consequência da primeira. Para o nosso exercício que se segue, utilizaremos a elaboração original de Peirce, isto é, o pragmatismo enquanto critério de significação.

Peirce, seguindo o exemplo de filósofos anteriores, como Descartes, Locke e Kant, buscou nas regras de funcionamento do pensamento o ponto de partida para boa parte de suas reflexóes. Uma das mais importantes entre essas reflexóes é a discussão sobre as crenças e as dúvidas - inspirada por uma crítica direta ao cartesianismo. Aliseda (2016, p. 144) ressalta: "Na epistemologia de Peirce, o pensamento é um processo dinâmico, essencialmente uma interação entre dois estados da mente: dúvida e crença." Ora, em 1877, entre uma série de artigos publicados, Peirce traz a público o famoso texto denominado $A$ 
fixação da crença, no qual o autor destrincha essa relaçáo permanente entre crenças e dúvidas, no pensamento, terminando a sua exposiçấo com quatro métodos possíveis para se fixar uma crença e determinar, dessa forma, o fim da dúvida.

Ao dar início à caracterizaçáo das crenças e das dúvidas, Peirce começa pela seguinte frase: "Geralmente sabemos quando queremos fazer uma pergunta e quando queremos pronunciar um julgamento, pois há uma diferença entre a sensação de duvidar e a de crer" (PEIRCE, EP, 1:114)3 ; o que se segue é um detalhamento dessa frase. A começar pela crença, esta é o estado da mente que determinará, indiretamente, as nossas açôes. O autor prossegue: "A essência da crença é o estabelecimento de um hábito" (PEIRCE, CP, 5.398, grifo nosso) $)^{4}$, e o hábito, por sua vez, determina as nossas açóes. A respeito de tais constataçóes sobre a crença, Peirce dirá que elas encerram três principais características: "Primeiro, [a crença] é algo do qual nós estamos cientes; segundo, ela apazigua a irritaçâo da dúvida; e, terceiro, envolve o estabelecimento, em nossa natureza, de uma regra de açáo ou, digamos, de um hábito." (PEIRCE, CP, 5.397, grifo do autor). Por outro lado, a dúvida, como dissemos, é o estado mental contrário ao da crença e, por isso, na ausência de um, encontra-se o outro.

Nota-se, pois, que essa relaçáo entre o crer e o agir leva em consideraçâo não só a crença, mas também a dúvida, uma vez que, quando não há crença e, consequentemente, um hábito mental que determine a ação, entâo a dúvida se tornará um empecilho prático. No entanto, ao contrário do que poderia parecer, Peirce entende que a dúvida tem também uma importância fundamental. Enquanto a crença, determinadora de hábitos, é o que nos leva a agir de certa maneira, a dúvida é aquela que nos leva a investigar e questionar o mundo que nos envolve, pois nos irrita e, consequentemente, impele-nos a retornar ao estado de crença.

Peirce (EP, 1:114) dá a essa condição de insatisfação o nome de "irritaçáo da dúvida". Esse estado de irritaçáo, de incerteza, faz com que busquemos nos ater a uma nova crença, o quanto antes, para dar fim à dúvida - quanto ao estado de crença, não desejamos evitá-lo e, muito menos, alterá-lo em direção a outra crença. Nesse sentido, a dúvida também nos leva à açâo, mas de outra

\footnotetext{
${ }^{3}$ Essential Peirce (PEIRCE, 1992, 1998). Nas citaçôes, o primeiro número após a sigla indica o volume e os demais, após dois pontos, se referem às páginas.

${ }^{4}$ Collected Papers (PEIRCE, 1931-1958). Nas citaçôes, o primeiro número após a sigla indica o volume e os demais, após o ponto, săo atinentes ao parágrafo.
} 
forma. Enquanto as crenças e os hábitos nos colocam sob uma disposição para agir de determinada maneira, quando a necessidade surgir, as dúvidas nos encaminham à ação, justamente para que possamos terminá-la. À busca incessante por um estado de crença Peirce dá o nome de inquirição, enquanto Rodrigues (2017, p. 17) complementa:

\begin{abstract}
A irritação da dúvida nos impele a pesquisar, insatisfeitos que ficamos com nossas opinióes, num processo que só chega ao fim quando outra opiniáo capaz de sanar a dúvida é alcançada, seja ela verdadeira ou falsa. A verdade, por si só, não é capaz de nos impelir a investigar ou sanar nossas dúvidas, porque é independente de nós. Daí a importância do método: não basta fixar a crença, é preciso fixar crenças verdadeiras.
\end{abstract}

De acordo com as palavras de Rodrigues, vemos que, buscando escapar do estado de irritação da dúvida em direção ao estabelecimento de uma crença, podemos incorrer em erros consequentes de crenças que não sejam verdadeiras. Para que isso não aconteça, é necessário que fixemos uma crença adequadamente, a fim de que futuramente não caiamos novamente em um estado de dúvida. Buscando esclarecer essa tarefa, Peirce descreve quatro métodos de fixação da crença. Os três primeiros (tenacidade, autoridade e a priori), cada qual a seu modo, não são indicados pelo autor para a fixação duradoura de crenças.

O último e mais importante entre os quatro métodos de fixação da crença propostos por Peirce é o método científico. Iniciamos a explicação sobre esse método com uma frase do autor, a qual sintetiza bem a necessidade que temos dele: "Para satisfazer nossas dúvidas, portanto, é necessário que seja encontrado um método pelo qual nossas crenças possam ser determinadas por nada que seja humano, mas por alguma permanência externa - por algo sobre o qual nosso pensamento não tenha efeito.” (PEIRCE, CP, 5.384). Como podemos apreender, a partir das palavras de Peirce, o método científico - ou a própria ciência - supera os outros métodos, na medida em que independe do homem para que se decida sobre aquilo que deve ou não ser acreditado, mas se baseia tăo somente na realidade. Essa realidade, por sua vez, é algo que afeta os nossos sentidos segundo regras e leis, que, por serem externas às nossas opiniōes, não dependem delas. Somos nós, com as nossas próprias crenças, que devemos nos adequar à realidade, e não o contrário, como ocorre nos outros três métodos de fixação. Por mais que a busca pela compreensão de tal realidade possa não parecer algo facilmente alcançável, “[...] a ideia de que há 
uma realidade se torna um postulado prático da razão" (DE WAAL, 2007, p. 37), que deve assumi-la e tentar compreendê-la.

Ademais, as crenças a serem fixadas a partir do método científico necessitam de um consenso entre indivíduos, para que possam se estabelecer de forma duradoura. Uma comunidade de indivíduos - de cientistas, no caso das pesquisas de opinião pública, por exemplo - contribui para que, por meio do método científico, da inquirição, se chegue a um consenso que ateste a validade daquela opiniāo ou crença. No entanto, poder-se-ia questionar sobre as possibilidades concretas de se auferir a realidade e, consequentemente, uma validade duradoura sobre determinada crença - mesmo que por meio da inquirição e apoiada sobre um consenso. A fim de responder a esse questionamento, pensemos no seguinte:

Peirce não somente acreditava que a inquirição futuramente nos levaria às respostas certas, ele também assegurava que em muitos casos já encontramos a resposta correta, muito embora náo sejamos capazes de dizer para uma questão particular qualquer que a encontramos. Dessa maneira, Peirce procurou cunhar uma terceira opinião entre o ceticismo e o dogmatismo, que ele denominou falibilismo. (DE WAAL, 2007, p. 37).

O falibilismo é o postulado segundo o qual a construção de um certo conhecimento pode se mostrar falsa e, por conseguinte, falhar. Sob ele, supõese que, no caso de algo como isso ocorrer, o conhecimento até então portado deva ser abandonado (PEIRCE, CP, 7.108-109). Igualmente, as crenças fixadas por meio do método científico carregam essa característica. Em métodos como o de tenacidade ou o a priori, a crença somente se torna dúvida quando confrontada com as opinióes de outros indivíduos, ao passo que, no caso do método científico, a crença se torna dúvida, ao ser confrontada pela própria realidade que a desmente.

Nesse sentido, o método de fixação científico se aproxima daquilo que traz unidade ao pragmatismo, independentemente de qual corrente do pragmatismo se adote, a saber, a soberania da prática sobre a intuição na busca pela compreensão da realidade. Depois de $A$ fixação da crença, Peirce publicou, no ano de 1878, outro importante artigo denominado Como tornar nossas ideias claras, no qual viria a introduzir a conhecida máxima pragmática. A discussão central tem por objetivo - mais uma vez - desenvolver uma crítica à filosofia de Descartes e, principalmente, ao seu método para identificar as ideias claras e distintas. Como o próprio nome do artigo sugere, Peirce propóe 
meios para tornar claras as nossas ideias, resultando no que é descrito por De Waal (2007, p. 39) como "uma teoria da significação".

De acordo com Peirce, ao tentarmos definir - dar significado - a um conceito, podemos atingir três níveis graduais de clareza sobre a ideia que esse conceito representa. O primeiro dos três níveis propostos é o seguinte: "Uma ideia clara é definida como uma ideia que é de tal forma apreendida que será reconhecida onde quer que seja encontrada e, portanto, nenhuma outra será confundida com ela." (PEIRCE, EP, 1:124). Estão incluídas aqui ideias como a de "cadeira" ou a de "cachorro". O segundo nível de clareza, aquele que mais se aproxima do que sustentava Descartes - e os lógicos adeptos de suas teorias - quanto às suas ideias claras e distintas, por sua vez, é o seguinte:

Uma ideia distinta é definida como aquela que não contém nada que não esteja claro. Isto é linguagem técnica; pelo conteúdo de uma ideia, os lógicos entendem o que está contido em sua definição. Então uma ideia é claramente apreendida, segundo eles, quando podemos dar uma definição precisa dela em termos abstratos. (PEIRCE, EP, 1:125, grifo do autor).

Nesse segundo nível, estão incluídas ideias mais abstratas que as do primeiro nível, como, por exemplo, a de "ouro", que é definido como o elemento com o número atômico 79 - isso o distingue, na medida em que nenhum outro elemento possui esse mesmo número atômico, ou seja, nenhum outro elemento possui o mesmo número de prótons em seu núcleo (DE WAAL, 2007, p. 40). A depender do caso, no entanto, esses dois primeiros níveis de clareza podem nos fazer incorrer em enganos. Por esse motivo, Peirce desenvolve um terceiro nível, o qual, associado à sua "teoria da significação", resulta na máxima pragmática, que funcionaria como uma regra para atingir o mais alto nível de clareza, no momento de definição de uma ideia ou conceito: "Considere quais efeitos, que poderiam concebivelmente ter consequências práticas, concebemos que tenha o objeto de nossa concepção. Então, nossa concepção desses efeitos é o todo de nossa concepção do objeto." (PEIRCE, EP, 1:132).

A máxima pragmática, apesar de complexa à primeira vista, deixanos entrever em seu interior a importância da ação e, por consequência, das crenças e hábitos (como vimos anteriormente, os hábitos mentais estabelecidos por crenças são, justamente, disposiçôes para a ação). Segundo Peirce, “[...] o que algo significa é simplesmente quais hábitos ele envolve." (PEIRCE, EP, $1: 131)$. Isto se dá dessa forma, pois, conforme a máxima, definimos um certo 
conceito de acordo com os efeitos práticos que concebemos a respeito dele, relacionando, dessa forma, o ato de definir um conceito ao ato de inquirir a realidade. Ademais, ao refletirmos sobre o pragmatismo peirciano, a partir de sua máxima original, constatamos que ele foi pensado como um meio para se clarificar ideias fundadas no compartilhamento de significados e experiências práticas, no interior de uma determinada comunidade. Determinadas ideias, como a de "fogo", por exemplo, são expressas e entendidas, pois o significado atrelado a ela se baseia em experiências vividas e compartilhadas dentro de uma comunidade e que suscitam, em seus indivíduos, certas crenças, hábitos e emoçóes.

Alguns anos depois, já após a construção da sua teoria semiótica, Peirce revisaria alguns pontos do seu pragmatismo ${ }^{5}$ e, junto com ele, a sua máxima pragmática. A principal mudança que o autor trouxe, naquele momento, se encontra no caráter psicológico da máxima original, que, àquela altura, era considerada por ele como algo negativo. Por esse motivo, tentou trazê-la à luz da semiótica, a fim de tornar lógico aquilo que era psicológico. Vejamos, pois, como ficou a reformulação da máxima feita nesse segundo momento: "O teor intelectual inteiro de qualquer símbolo consiste no total de todos os modos gerais de conduta racional que, condicionalmente sobre todas as possíveis e diferentes circunstâncias e desejos, decorreriam da aceitação do símbolo." (PEIRCE, EP, 2:346). Nessa fase, a máxima passa a se referir aos efeitos práticos que seriam concebidos (note-se o futuro do pretérito) por uma comunidade de intérpretes, caso fossem esgotados todos os recursos possíveis.

\section{O MODELO TRADICIONAL DE PESQUISAS DE OPINIÁO PÚBLICA}

As pesquisas de opinião pública tradicionais, tais como as conhecemos até hoje, nasceram nos Estados Unidos dos anos 1930, ou seja, no seio do funcionalismo americano, o que influenciou as metodologias e teorias aplicadas ao estudo da opiniáo pública, nesse modelo. Até então, era comum que se pesquisasse ou mensurasse a opinião pública por meio das chamadas straw polls (GOIDEL, 2011, p. 11), enquetes sem valor científico - feitas sem fundamentaçôes metodológicas estatísticas - realizadas sobretudo por veículos midiáticos. Nas eleiçóes americanas presidenciais de 1936, entretanto,

5 Naquele momento, o autor passa a chamar o pragmatismo de pragmaticismo, para que suas elaboraçôes originais nẫo fossem mais confundidas com outras que haviam sido criadas por terceiros. Depois de algum tempo, Peirce voltaria a utilizar o termo pragmatismo, a fim de se referir às suas próprias elaboraçôes. 
as pesquisas de George Gallup obtiveram um sucesso sem precedentes, na previsão dos resultados, e, com isso, teve-se início uma nova era nos estudos da opinião pública.

Em publicação do ano seguinte ao da eleição, Crossley (1937), um pesquisador da opinião pública, examinou os potenciais limites das novas opinion polls e os problemas com as enquetes utilizadas até entâo. Dentre os pontos discutidos por Crossley, em seu texto, está a diferença metodológica entre os dois modelos de pesquisa existentes na época: um deles, as opinion polls, criadas por Gallup, contava com amostras menores, mas um rigor estatístico que garantia a validade representativa das amostras a serem analisadas, ao passo que as straw polls eram abertas a todos os que quisessem respondê-las, mas não eram representativas. Crossley (1937, p. 25, tradução nossa, grifo nosso) escreveu sobre o que se pensava sobre isso, antes da eleição de 1936:

Outras duas grandes diferenças de opiniáo existiam. Um lado argumentou que o Literary Digest [veículo midiático que fazia as mais importantes previsôes eleitorais da época] não poderia estar errado por causa de sua tremenda amostra, isto é, número de votos. O outro lado argumentou que uma amostra relativamente pequena poderia ser usada, se cientificamente distribuída.

Pelo relato de Crossley, podemos perceber que, à época, a utilização de fundamentaçôes estatísticas em pesquisas de opinião pública não apenas era uma novidade, como também não havia um consenso sobre a sua necessidade. No entanto, depois do sucesso no contexto eleitoral de 1936 - e especialmente depois da Segunda Guerra Mundial - as metodologias utilizadas por Gallup foram elevadas a um nível de extrema relevância, nos estudos de opinião pública (SPLICHAL, 2012, p. 32).

Com o estabelecimento das pesquisas de opinião pública científicas (as opinion polls), enquanto ferramentas para mensuração e previsão da opinião pública, muitas perspectivas se alteraram nos estudos de opinião pública - em especial as epistemológicas. A conciliação entre teoria e metodologia tornouse um problema central nos estudos de opinião pública, especialmente em trabalhos de natureza teórica. A colocação desse novo problema (como conciliar as teorias que procuram explicar a opinião pública com as metodologias aplicadas ao seu estudo empírico) promoveu debates epistemológicos entre diversas correntes, durante o século XX. Ainda nos anos 50, olhando para a primeira metade do século que se passara, alguns autores, como Hyman (1957, 
p. 55-57), apontaram para o embate epistemológico que se havia constituído e que, factualmente, persiste até os dias de hoje.

Em Public Opinion, Glynn et al. (2016) nos apresentam uma categorização de definiçôes possíveis para o conceito de opiniāo pública, de acordo com cinco principais correntes teóricas ${ }^{6}$ que ganharam força desde o início do século passado. Apesar de serem diversas, os autores afirmam que a primeira das categorias, na qual "[a] opinião pública é uma agregação de opiniōes individuais", é indubitavelmente a mais difundida e adotada, seja por pesquisadores, seja pelo senso comum. Um fator determinante para a consolidação dessa visão de opinião pública e para propagação da metodologia aplicada no modelo tradicional é a sua base científica, possibilitada pelo rigor estatístico na coleta dos dados a serem analisados posteriormente. Segundo Goidel (2011, p. 18), foi somente a partir do momento em que se passou a estudar a opinião pública, por meio do modelo inaugurado pelas opinion polls de Gallup, que esse objeto adquiriu uma construção científica de fato. As bases metodológicas utilizadas inicialmente no modelo tradicional de pesquisas permaneceram inalteradas em sua essência até mesmo nas pesquisas realizadas em localidades fora dos Estados Unidos, como é o caso do Brasil. Muito disso se deve a certos institutos de pesquisa, como, por exemplo, o IBOPE, criado ainda na década de 40 (BIROLI; MIGUEL; MOTA, 2011, p. 68-69).

Nesse modelo tradicional de pesquisa, a representação da opinião pública de uma determinada população pode ser estatisticamente extrapolada em função das amostras que são colhidas por meio de surveys - isto se forem devidamente obedecidas as adequaçóes demográficas da área em que se insere essa população. Assinala Macreadie (2011, p. 6):

Pesquisas de opinião quantitativa referem-se a surveys que medem a opiniâo de uma amostra de pessoas. Estas são particularmente úteis em cenários eleitorais, em que as respostas são relativamente diretas e são restritas a respostas de tipo "sim/não". Pesquisas de opinião quantitativas frequentemente envolvem questionários, entrevistas cara-a-cara, pesquisas por telefone e pesquisas online/por e-mail.

\footnotetext{
${ }^{6}$ A saber: (1) A opiniâo pública é uma agregação de opiniôes individuais; (2) A opiniâo pública é um reflexo das crenças da maioria; (3) A opiniấo pública é encontrada no choque entre interesses de certos grupos; (4) A opinião pública reflete a influência da mídia e das elites; (5) A opinião pública é uma ficção.
} 
Dada a representatividade estatística propiciada pelas pesquisas de opinião pública tradicionais, estas têm como principal objetivo a previsão de cenários futuros, especialmente em contextos eleitorais.

Como foi frisado anteriormente, alguns autores destinaram críticas profundas a esse modelo de pesquisa, nas últimas décadas, especialmente no que diz respeito ao significado dado à opiniáo pública dentro dele, ou seja, ao entendimento de que a opinião pública é a agregação ou soma de opinióes individuais. Destacamos aqui dois expoentes, entre esses críticos: Herbert Blumer e Pierre Bourdieu.

Em meados do século XX, em plena ascensão das opinion polls, Blumer destoou do paradigma em voga, referente à visão quantificadora da opiniáo pública, e propôs um novo entendimento que era essencialmente conversacional e baseado na interação social. Segundo Anstead e O'Loughlin (2015, p. 214, tradução nossa), Blumer alicerçou suas críticas às pesquisas de opinião pública sobre três alegaçôes: "O público é social, a opinião pública é hierárquica e a verdadeira opinião pública exige que o público se envolva em debates políticos." Especificamente sobre o modelo tradicional de pesquisa, Blumer produziu críticas contundentes quanto à fundamentação teórica adotada pelos pesquisadores da opinião pública e sobre a aplicação indevida das técnicas de pesquisa, chegando a questionar, inclusive, a natureza científica das pesquisas de opiniáo pública. Segundo o autor (BLUMER, 1986, p. 195197), faltaria ao modelo tradicional de pesquisa um objeto abstrato e genérico, "opiniâo pública", o qual fosse isolado pelos pesquisadores, de modo a guiar a produção das pesquisas. Ademais, o autor considerava que não há esforço por parte dos pesquisadores para produzir generalizaçóes ou critérios que caracterizem ou distingam a opinião pública, a fim de explicá-la e levar adiante o seu entendimento. Nas palavras de Blumer (1986, p. 196-197): "O trabalho deles [pesquisadores] se trata meramente da aplicação de suas técnicas. Eles não estão preocupados com análises independentes da natureza da opinião pública, para julgar se a aplicação das suas técnicas se encaixa a tal natureza.”

Por sua vez, Bourdieu (1987) faz, em A opiniāo pública não existe, uma crítica epistemológica às pesquisas de opinião pública do modelo tradicional, opondo-se à interpretaçáo da opiniáo pública, enquanto agregaçáo ou soma de opinióes individuais, ou seja, combatendo essa visão essencialmente quantitativa. No texto, o sociólogo tece uma linha de raciocínio que procura desvendar e refutar algumas premissas estabelecidas por trás da produção das pesquisas. Para tanto, Bourdieu identifica três postulados, os quais, nas 
palavras dele, "[...] implicam, parece-me, toda uma série de distorçóes que são observadas, mesmo quando todas as condiçóes do rigor metodológico sáo obedecidas na coleta e análise dos dados" (BOURDIEU, 1987, p. 138, grifo nosso), ou seja, distorçóes nas pesquisas que independem dos protocolos metodológicos usados pelos grandes institutos. Esses postulados são os seguintes: "[...] toda pesquisa de opinião supóe que todo mundo pode ter uma opinião; ou, em outras palavras, que a produção de uma opinião está ao alcance de todos" (BOURDIEU, 1987, p. 137); “[...] todas as opinióes se equivalem" (BOURDIEU, 1987, p. 138); e "[...] no simples fato de fazer a mesma pergunta para todo mundo acha-se implícita a hipótese de que existe um consenso sobre os problemas, em outras palavras, de que existe um acordo sobre as perguntas que merecem ser feitas." (BOURDIEU, 1987, p. 138).

Assim como Blumer, Bourdieu (1987, p. 137-138) defendia que a equidade de valor entre as opiniōes dos indivíduos - um dos princípios das pesquisas - é enganosa, por mais que isso soasse antidemocrático. Ao contrário, os autores não veem problema em afirmar que certos cidadãos são mais influentes do que outros, e que isso tem impactos sobre a opiniáo pública (GLYNN et al., 2016, p. 16). Em suma, ambos entendem haver certos problemas com as pesquisas de opiniáo pública que devem ser pensados, antes mesmo da ida dos pesquisadores ao campo, problemas estes de natureza epistemológica. Tanto para os dois autores citados quanto para as correntes críticas que deles decorreram, a opinião pública é mais complexa do que a representação obtida pelas tấo bem-sucedidas opinion polls, uma vez que esse objeto, segundo eles, seria constituído no choque social nascido da interação entre os interesses de diferentes grupos e indivíduos.

\section{O NOVO MODELO DE PESQUISAS DE OPINIÃo PÚBLICA}

O problema de conciliação entre teoria e metodologia, nos estudos de opiniấo pública, não apenas persistiu até os dias de hoje, como foi reacendido pelo que Couldry e Hep (2016, p. 45-47) chamam de onda de digitalização, caracterizada pelos adventos dos computadores, da Internet e, mais recentemente, das mídias sociais. Isto se dá dessa forma, pois, na medida em que há um desenvolvimento material e tecnológico profundo, na sociedade, alteram-se também as próprias dinâmicas da esfera pública, que adquire uma faceta digital. Consequentemente, a opiniâo pública também passa a se originar e ser propagada nesse novo ambiente, especialmente em seu formato 
mais refinado: o dos sites denominou dataísmo (a crença no poder dos dados e das instituiçóes que deles dispóem), em um contexto onde os objetos das mais diversas áreas das ciências, tais como as ciências da computação, a física, a matemática, a ciência política, a bioinformática, a sociologia etc., vêm sendo afetadas pelo crescente uso do Big Data (BOYD; CRAWFORD, 2012, p. 663), as opinióes dos indivíduos, por consequência, não escapam ao irrefreável movimento de datificação - em outras palavras, o tornar o mundo em dados quantificáveis passíveis de análises preditivas (MAYER-SCHÖNBERGER; CUKIER, 2013, 1.8).

Existem diferentes interpretações para o termo Big Data, provenientes das mais diversas áreas do conhecimento (DEMCHENKO, 2014, p. 105). Pensando no senso comum, podemos adotar a definição segundo a qual "[...] o rótulo 'Big Data' é usado para descrever um conjunto de práticas envolvendo a coleta, processamento e análise de grandes conjuntos de dados." (SCHÄFER; VAN ES, 2017, p. 15, tradução nossa). No entanto, como certas características se sobressaem e afetam contundentemente a maneira de se abordar o estudo da opinião pública, daremos também a nossa interpretação. Para além das grandes quantidades de dados, cremos que três aspectos caracterizam o Big Data, a saber: a velocidade, a exaustividade e a possibilidade de se utilizar modelos estatísticos não paramétricos.

De acordo com Kitchin e McArdle (2016, p. 7), a velocidade e a exaustividade são as características, as quais, em meio a tantas outras, distinguem ontologicamente o Big Data. A primeira delas, a velocidade, diz respeito à possibilidade de coleta ininterrupta (contínua) dos dados que constituem as amostras da pesquisa - com as metodologias tradicionais das ciências sociais, a coleta das amostras é feita ocasionalmente e, em alguns casos, com grande lapso temporal entre uma coleta e outra. Já a segunda, a exaustividade, concerne à possibilidade de se coletar e analisar o universo inteiro de uma determinada populaçấo $(n=a l l)$, ao contrário do que ocorre no modelo tradicional, quando, limitadas por questóes de tempo e custo, as amostras são estatisticamente extrapoladas, a fim de se representar a totalidade de um universo.

Somado à interpretação de Kitchin e McArdle, o terceiro aspecto que julgamos definir o Big Data é a possibilidade de se empregar modelos estatísticos náo paramétricos. Pensando nas transformaçóes que o Big Data traz para os processos científicos, Pietsch (2013, p. 12-13) destaca que as tradicionais análises paramétricas, elaboradas por meio de modelos verticais 
hierárquicos, dão lugar a modelos horizontais, que dispensam o uso de leis e regras gerais a priori, de maneira a se identificar correlaçóes no interior dos dados analisados. As análises de mídias sociais do novo modelo de pesquisa de opinião pública, feitas por meio de abordagens horizontais - onde os dados são colhidos e a parametrização só se dá a posteriori - permite que os parâmetros de análise sejam constituídos continuamente, conforme uma aplicação algorítmica intensiva sobre os dados.

Portanto, em produção paralela às pesquisas de opiniáo pública tradicionais, hoje temos aquelas que se utilizam das opçóes metodológicas possibilitadas por tais características, e que tanto podem se focar no estudo de opiniōes individuais (NEETHU; RAJASREE, 2013) quanto no da opinião pública em geral (O’CONNOR et al., 2010). Graças ao Big Data, o diferencial do novo modelo reside no uso de métodos e técnicas específicas para a coleta e análise dos dados que se diferenciam profundamente dos questionários e entrevistas - tipicamente adotados pelos institutos de pesquisa tradicionais. Em vez disso, nesse novo modelo, a coleta e análise dos dados é feita por meio do monitoramento de mídias sociais, como, por exemplo, o Facebook e o Twitter:

Metodologias de survey e polling [...] nos deram inúmeras ferramentas e técnicas para realizar medições representativas da opinião pública. [...] Com a ascensão dramática das mídias sociais baseadas em texto, milhóes de pessoas transmitem seus pensamentos e opinióes em uma grande variedade de tópicos. [...] entâo, minerar a opiniáo pública, a partir do conteúdo de textos livremente disponível poderia ser uma alternativa mais rápida e menos dispendiosa às pesquisas tradicionais. (O'CONNOR et al., 2010, p. 122, tradução nossa).

Aqui se coletam as postagens de texto dos usuários de mídias sociais para, em seguida, analisá-las enquanto opinióes de fato desses mesmos usuários. Entretanto, pela falta de representatividade demográfica dos usuários de mídias sociais, nesse modelo, não há a intenção de analisar individualmente as opiniōes e nem de prever cenários futuros, mas se busca, táo somente, monitorar o debate público realizado na Internet (RUEDIGER, 2018, p. 5-14) ou representar a opinião agregada da população [de usuários] sobre determinado assunto ou tópico (O’CONNOR et al., 2010, p. 125). Nesse modelo, não mais se utilizam os surveys, pois o pesquisador de campo e as técnicas tradicionais são substituídos pelas plataformas digitais e pelas técnicas que ensejam a coleta de dados dessas plataformas. 
Se, no modelo tradicional, a visualização dos dados é feita por meio de tabelas ou gráficos simples, no novo modelo, ela passa a ser feita através de grafos complexos. Nesse caso, os nós - representando usuários das mídias sociais (indivíduos ou organizaçóes) - se relacionam por meio de arestas, de forma a construírem grandes redes: "Parte-se da análise de como os nós se conectam e relacionam para realizar a análise que, posteriormente, pode agregar dados de atributos e outros. E as conexóes podem ser de diversos tipos, intensidades e direçóes." (SILVA; STABILE, 2016, p. 238). Isto é especialmente importante, pois se cria a possibilidade de uma análise da opiniáo pública fundamentada sobre as relaçôes entre diferentes atores (cidadãos, políticos, veículos jornalísticos, instituiçóes governamentais, corporaçôes etc.).

O resultado disso é uma representação - em larga escala - da opinião pública que náo mais se debruça sobre a agregação ou soma de opinióes individuais, porém, em quais grupos da sociedade interagem entre si - e de que forma - diante de determinados problemas ou tópicos de interesse. É possível determinar quais são os principais atores (indivíduos ou organizaçóes) da esfera pública digital, quais grupos contam com mais apoiadores e em que medida eles se relacionam, além de se tornar possível visualizar o movimento de formação e propagação da opinião pública, nas redes, em um dado espaço de tempo.

Em face disso tudo, afirmamos que não apenas os métodos e técnicas do estudo da opiniáo pública foram ampliados, mas o próprio entendimento do que é a opinião pública também é impactado. Herbst (2011) enfatiza que, com a chegada da Internet e das mídias sociais, o embate epistemológico entre perspectivas teóricas e empíricas da opinião pública foi atualizado. Para a autora, há uma luta subterrânea, nesse campo de estudo, constituída por duas abordagens opostas que podem ser encontradas em qualquer época: uma abordagem quantificadora e uma conversacional, ou, em outras palavras, "[...] opiniâo pública como uma agregação de opiniốes individuais e opinião pública como uma conversa não quantificada, mas poderosa.” (HERBST, 2011, p. 88).

O que aqui chamamos de modelo tradicional está incluído na abordagem quantificadora, ao passo que o que consideramos novo modelo está incluído na abordagem conversacional. Finalmente, a autora reconhece que, com o uso das novas tecnologias, podemos identificar e estudar traços da opiniâo pública que eram evocados por autores críticos ao modelo tradicional, 
como Blumer, e que náo podem ser plenamente apreendidos pelas opinion polls (HERBST, 2011, p. 96).

\section{ANÁlISE PRAGMÁTICA SOBRE A TRANSIÇÃO ENTRE MODELOS}

Julgamos necessário começar defendendo a ideia de que ambos os modelos de pesquisa aqui abordados constituem investigaçóes científicas e que, por consequência, se encontram inseridos no método científico de fixação de crenças. Segundo Peirce, como vimos, a realidade existe independentemente daquilo que nós pensemos ou creiamos acerca dela, de sorte que o método científico deve, justamente, fixar a nossa opinião ou crença sobre a realidade, de acordo com a própria realidade. Por sua vez, a opiniāo pública, enquanto objeto investigado a partir do método científico, deve, ela mesma, ser um objeto real e independente das pesquisas e metodologias a serem utilizadas para estudá-lo.

Pensamos, pois, que a opinião pública é um fenômeno que se encontra na realidade (seja aquela opiniáo pública referida pelos filósofos da modernidade, seja aquela que é possibilitada pelas novas tecnologias digitais contemporâneas), e qualquer que seja a realidade desse objeto, ele já existia anteriormente à invenção das pesquisas científicas de Gallup ou do monitoramento de mídias sociais. Por mais que o fenômeno "opinião pública” seja dialeticamente afetado pela própria produção e publicização das pesquisas, a sua realidade é algo já notado há séculos, ou seja, caso a produção das pesquisas de opinião pública cessasse ou nunca tivesse existido, em nada ou pouco - mudaria o fato de a opinião pública ser um fenômeno presente na realidade e, ainda mais profundamente, ser um fenômeno complexo (vide os séculos de intensos debates sobre a sua natureza e funcionamento).

No entanto, aquilo que se entendia por "opiniáo pública" foi abruptamente alterado com a invenção das pesquisas científicas, ao passo que, na prática, não vemos a opinião pública, enquanto fenômeno complexo e real, o qual nasce e se desenvolve no interior da esfera pública, sendo efetivamente impactada por essa invenção. $\mathrm{O}$ uso que se faz da opinião pública como soma ou agregação de opiniōes individuais é, sem dúvida, diferente daquele que se fazia antes das pesquisas, quer para previsão de eleiçóes, quer para tomada de decisóes por parte de políticos ou corporaçóes. Logo, para o uso que se faz da opinião pública, as mudanças trazidas pelas opinion polls foram, de fato, profundas. Todavia, essas mudanças não impactaram profundamente a 
natureza da própria opinião pública, nem possibilitaram uma compreensão mais complexa do objeto opiniáo pública, enquanto fenômeno da realidade.

Isto é, apesar de impactar grandemente o uso que se faz da opinião pública, a invenção de Gallup não teve esse mesmo grau de impacto para a obtenção de uma crença acerca da natureza da opiniáo pública que fosse baseada na realidade do objeto. Poder-se-ia argumentar que o modelo tradicional, com pesquisas como as do Instituto Datafolha e IBOPE, traz, de alguma forma, uma compreensão mais profunda do objeto "opinião pública". Quanto a isso, nós estamos de acordo com as críticas feitas por Blumer e Bourdieu ao modelo tradicional de pesquisas, segundo as quais a opiniáo pública é mais complexa do que a mera soma ou agregação de opinióes individuais, sendo elas resultantes do choque de interesses e relaçóes de diversos atores sociais (indivíduos e grupos). Ou, ainda, estamos de acordo com o entendimento de Herbst, para quem a "verdadeira" opinião pública é um fenômeno conversacional complexo - e, por esse motivo, dificilmente quantificável.

No fundo, o significado do conceito de opinião pública é alterado com a ascensão de cada modelo de pesquisa. Se conceitos como os de "cadeira" e "ouro" se encontravam inseridos nos dois primeiros níveis de clareza das ideias, o conceito de "opinião pública" está no terceiro nível. Lembremos, pois, que o terceiro nível de clareza das ideias associa o ato de definir um conceito ao ato de inquirir a realidade, e isso é precisamente o que vemos nas pesquisas de opinião pública. Ao tratarmos dos dois modelos (o tradicional e o novo), notamos que, para além de um apanhado de procedimentos metodológicos, cada um deles compreende a opinião pública conforme uma base epistemológica - a qual, por sua vez, é resultante de um paradigma definido. De um ponto de vista pragmático, isso é absolutamente relevante, porque, em última análise, o que cada modelo de pesquisa entende por opiniáo pública - ou seja, o significado dado ao objeto "opinião pública" - afeta fundamentalmente o que se buscará conhecer a respeito dela. Por consequência, o significado desse objeto está associado aos efeitos práticos da adoção de um modelo ou outro.

O método científico empregado para inquirir a realidade a propósito do que é a opiniấo pública, a saber, as próprias pesquisas de opinião pública, deveria, segundo o pragmatismo de Peirce, adequar a nossa crença sobre o fenômeno com o que o fenômeno é, na realidade. Nesse sentido, assumindo as posiçóes de Blumer, Bourdieu e Herbst, o modelo que melhor nos ajudaria a definir uma significação do objeto "opinião pública" é o novo modelo. Neste, o significado de "opiniấo pública”, ainda que quantificável, encontra-se nas 
relaçôes entre diferentes atores da sociedade, e não na opiniáo individual de cada um que compóe a esfera pública. Portanto, ao realçar a complexidade do aspecto conversacional do fenômeno, o novo modelo concebe por opiniáo pública algo mais próximo do que é visto na realidade da esfera pública digital. As consequências práticas (referenciando a máxima pragmática) da adoção desse significado condizem mais com o que é visto na realidade, do que as consequências práticas da adoção do significado dado à opinião pública no modelo tradicional, no qual a opiniâo pública é compreendida como a soma ou agregação de opinióes individuais.

Para Peirce, a realidade é algo que seria representado virtualmente - e verdadeiramente - pela opiniáo de uma comunidade ideal de pesquisadores que tivesse a seu dispor todo o tempo e recursos necessários. Trazendo isso para o nosso contexto, temos a seguinte compreensão: a opinião pública é um fenômeno da realidade que se procura apreender; em uma situação ideal, os pesquisadores da opiniâo pública, diante da possibilidade de tempo e recursos infinitos, encontrariam, finalmente, a verdadeira opinião pública, ou seja, a opiniáo pública tal como ela é, na realidade. Peirce dizia que sim, nós poderíamos já estar sob a posse dessa opiniáo final e verdadeira sobre nosso objeto de estudo, mas, infelizmente, não temos como ter a certeza sobre isso.

Nesse sentido, as metodologias das quais dispomos hoje talvez não sejam suficientes para apreendermos o fenômeno da opinião pública, em sua complexidade mais profunda. De todo modo, certas metodologias apresentam resultados mais complexos da opiniáo pública do que outras - embora com certos problemas, como o da representatividade demográfica. Portanto, a partir dos modelos que temos sob nossa posse, hoje, cabe aos pesquisadores da opinião pública buscarem, de acordo com o método científico consensual e sua inerente possibilidade de falha e constante revisão, uma compreensão do fenômeno opiniấo pública que associe o significado desse objeto àquilo que se encontra complexamente presente na realidade.

\section{ConsideraçóEs Finais}

Com a chegada da onda de digitalização, vieram à tona tecnologias como a Internet, as mídias sociais e, mais recentemente, o Big Data. As transformaçôes sociais e materiais trazidas por tais tecnologias consolidaram uma faceta da esfera pública que é essencialmente digital, o que acabou por impactar profundamente o estudo da opinião pública. Não apenas novas 
metodologias para análise e mensuração da opiniáo pública surgiram, mas a compreensão e o significado sobre o objeto foram alterados. Se, com a ascensão do modelo tradicional, o até então teórico e complexo entendimento filosófico da opiniâo pública foi abafado por uma visão quantitativa, na qual a opinião pública é interpretada como a soma ou agregação de opiniôes individuais, com a ascensão do novo modelo, abre-se espaço para o retorno de uma visão conversacional da opiniáo pública.

Aos olhos do pragmatismo de Peirce, essas mudanças são de extrema relevância, uma vez que as pesquisas de opiniấo pública atuam como meios para que possamos inquirir a realidade a respeito da opiniáo pública ela mesma. Após séculos de debate teórico em torno da natureza desse fenômeno, temos em mãos hoje métodos e técnicas de pesquisa empírica que permitem uma apreensão - ainda que embrionária - da opinião pública, baseada em uma interação complexa entre atores sociais.

Finalizaremos este artigo, reafirmando que não vemos os dois modelos de pesquisa de opinião pública aqui abordados como sendo excludentes. Pelo contrário, consideramos que um trabalho coordenado entre pesquisadores de ambas as abordagens, aliado a explicaçóes teoricamente fundamentadas sobre o objeto "opinião pública", pode levar adiante uma compreensão mais profunda e historicamente suportada desse objeto.

ROMANINI, V.; CALDAS, P. Public opinion and technology: the impacts of big data in public opinion studies under the look of pragmatism. Trans/form/ação, Marília, v. 44, n. 4, p. 375-398, Out./Dez., 2021.

\begin{abstract}
In this article, we investigate how the study of public opinion is influenced by public opinion polls as they work as a means of inquiring reality. With the growing movement of datification in the world, scientific and technological transformations emerge and impact the field of public opinion studies. Today, on the one hand, we have traditional opinion polls and, on the other, the researchers made possible by the advent of Big Data. In addition to a collection of methodological protocols, each model encompasses a meaning of "public opinion", going back to the old epistemological clash between theory and methodology present in this field of study. We will describe the main differences between these two models and then, under the perspective of Peirce's pragmatism as a theory of meaning, to analyze the transition we are going through today.
\end{abstract}

Keywords: Public opinion polls. Big Data. Meaning. Pragmatism. 


\section{REFERÊNCIAS}

ALISEDA, A. Belief as a habit. In: WEST, D.; ANDERSON, M. (ed.) Consensus on Peirce's Concept of Habit: Before and Beyond Consciousness. Suisse: Springer: 2016. ANSTEAD, N.; O'LOUGHLIN, B. Social media analysis and public opinion: The 2010 UK general election. Journal of Computer-Mediated Communication, v. 20, n. 2, p. 204-220, 2015. Disponível em: https://onlinelibrary.wiley.com/doi/full/10.1111/ jcc4.12102. Acesso em: 10 nov. 2020.

BIROLI, F.; MIGUEL, L.; MOTA, F. Mídia, eleições e pesquisa de opinião no Brasil (1989-2010): um mapeamento da presença das pesquisas na cobertura eleitoral. Revista Compolítica, n. 1, v. 1, ed. mar./abr., p. 68-89, 2011. Disponível em: http://compolitica. org/revista/index.php/revista/article/view/4. Acesso em: 10 nov. 2020.

BLUMER, H. Public Opinion and Public Opinion Polling. In: BLUMER, H. Symbolic Interactionism, Berkeley e Los Angeles: University of California Press, 1986.

BOURDIEU, P. A opinião pública não existe. In: THIOLLENT, M. Crítica metodológica, investigaçáa social e enquete operária. 5 ed. São Paulo: Polis, 1987. p. $137-151$.

BOYD, D.; CRAWFORD, K. Critical questions for Big Data: provocations for a cultural, technological, and scholarly phenomenon. Information, Communication $\boldsymbol{\alpha}$ Society, Abingdon, v. 15, n. 5, 2012. Disponível em: https://www.tandfonline.com/doi/ abs/10.1080/1369118X.2012.678878. Acesso em: 10 nov. 2020.

BURKS, A. The Essential Peirce: Selected Philosophical Writings v. 1-2. Bloomington e Indianapolis: Peirce Edition Project, 1992, 1998.

COUlDRY, N.; HEP, A. The Mediated Construction of Reality. Cambridge: Polity, 2016.

CROSSleY, A. Straw Polls in 1936. The Public Opinion Quarterly, p. 24-35, jan. 1937. Disponível em: https://www.jstor.org/stable/i328041. Acesso em: 10 nov. 2020.

DEMCHENKO, Y. et al. Addressing big data issues in Scientific Data Infrastructure. In: 2013 INTERNATIONAL CONFERENCE ON COLLABORATION TECHNOLOGIES AND SYSTEMS (CTS), 2013, San Diego, CA. Anais [...]. San Diego, CA, 2013, p. 48-55. Disponível em: https://ieeexplore.ieee.org/ document/6567203. Acesso em: 10 nov. 2020.

DE WAAL, C. Sobre Pragmatismo. Tradução: Cassiano Terra Rodrigues. São Paulo: Loyola, 2007.

GLYNN, J. et al. Public Opinion. 3. ed. Boulder: Westview Press, 2016.

GOIDEL, K. Public Opinion Polling in a Digital Age: Meaning and Measurement. In: GOIDEL, K. (ed.). Political polling in the digital age: The challenge of measuring and understanding public opinion. Batin Rouge: Louisana State University Press, 2011.p. 11-27. 
HERBST, S. (Un)Numbered Voices. In: GOIDEL, K. (ed.), Political polling in the digital age: The challenge of measuring and understanding public opinion. Baton Rouge: Louisana State University Press, 2011. p. 85-98.

HYMAN, H. H. Toward a theory of public opinion. Public Opinion Quarterly, v. 21, p. 54-60, 1957. Disponível em: https://academic.oup. com/poq/article-abstract/21/1/54/ 1886812? redirectedFrom=PDF. Acesso em: 10 nov. 2020.

KITCHIN, R.; MCARDLE, G. What makes Big Data, Big Data? Exploring the ontological characteristics of 26 datasets. Big Data \& Society, p. 1-10, jan./jun., 2016. Disponível em: https://journals.sagepub.com/doi/full/10.1177/2053951716631130. Acesso em: 10 nov. 2020.

MACREADIE, R. Public opinion polls. Parliamentary Library, v. 3, p. 1-46, 2011. Disponível em: https://apo.org.au/node/26371. Acesso em: 10 nov. 2020.

MAYER-SCHÖNBERGER, V.; CUKIER, K. Big Data. A Revolution that will transform how we live, work, and think. 1. ed. Londres: John Murray, 2013.

NEETHU, M.; RAJASREE, R. Sentiment Analysis in Twitter using Machine Learning Techniques. 4 ICCCNT, 2013. Disponível em: https://www.researchgate.net/ publication/269332365_Sentiment_analysis_in_twitter_using_machine_learning_ techniques. Acesso em: 10 nov. 2020.

O'CONNOR, B. et al. From Tweets to Polls: Linking Text Sentiment to Public Opinion Time Series. In: INTERNATIONAL AAAI CONFERENCE ON WEBLOGS AND SOCIAL MEDIA, 4., 2010. Disponível em: https://www.cs.washington.edu/ publications/tweets-polls-linking-text-sentiment-public-opinion-time-series. Acesso em: 10 nov. 2020.

PEIRCE, C. S. Collected Papers. v. 1-6, C. Hartshorne e P. Weiss, P. (ed.). v. 7-8, A. Burks (ed.). Cambridge: Harvard University Press, 1931-58.

PIETSCH, W. Big Data-the new science of complexity. In: MUNICH-SYDNEY TILBURG CONFERENCE ON MODELS AND DECISIONS, 6., 10-12 abr. 2013, Munich. Anais [...]. Munich, 2013. Disponível em: http://wolfgangpietsch.de/ publications/. Acesso em: 10 nov. 2020.

RODRIGUES, C. T. Peirce, Charles Sanders. In: CAMPILONGO, C.; GONZAGA, A.; FREIRE, A. (coord.). Enciclopédia jurídica da PUC-SP. Tomo: Teoria Geral e Filosofia do Direito. CAMPILONGO, C.; GONZAGA, A.; FREIRE, A. (coord. de tomo). 1. ed. São Paulo: Pontifícia Universidade Católica de São Paulo, 2017. Disponível em: https:// enciclopediajuridica.pucsp. br/verbete/58/edicao-1/peirce,-charles-sanders. Acesso em: 10 nov. 2020.

RUEDIGER, M. A. (coord..) Nem tão \#simples assim: o desafio de monitorar políticas públicas nas redes sociais. Caderno de Referência de Metodologia 1. 2. ed. Rio de Janeiro: FGV DAP, 2017. Disponível em: https://bibliotecadigital.fgv.br/dspace/ handle/10438/19436. Acesso em: 10 nov. 2020. 
SCHAEFER, M.; VAN ES, K. The Datafied Society - Studying Culture through Data. Amsterdam: Amsterdam University Press, 2017.

SPLICHAL, S. Public opinion and opinion polling: Contradictions and controversies. In: HOLTZ-BACHA C.; STRÖMBÄCK, J. (ed.). Opinion polls and the media: Reflecting and shaping public opinion. Basingtstoke: Palgrave Macmillan, 2012. p. 25-46.

VAN DIJCK, J. Confiamos nos dados? As implicações da datificação para o monitoramento social. Matrizes, São Paulo, v. 11, n. 1, jan./abr. 2017. Disponível em: http://www.revistas.usp. br/matrizes/article/view/131620. Acesso em: 10 nov. 2020. 
ROMANINI, V.; CALDAS, P. 